DOI: 10.20472/IAC.2018.041.014

\author{
ANNA MARIE FISKER \\ Department of Civil Engineering, University of Aalborg, Denmark \\ ANNA EVA UTKE HEILMANN \\ Department of Civil Engineering, University of Aalborg, Denmark \\ NINI CAMILLA BAGGER \\ Deprtment of Civil Engineering, University of Aalborg, Denmark
}

\title{
THE MOBILE SPROUT WAGON - AN INNOVATIVE NEW APPROACH TO IMPROVING PUPIL'S HEALTH THROUGH INTERDISCIPLINARY HANDS-ON FOOD ACTIVITIES
}

\begin{abstract}
:
In today's society there is a tendency that children are increasingly more and more detached and disconnected from the food they are eating; the origins of its components, and the process 'farm to fork'. This is an issue with wide-reaching consequences to health. In this paper we will seek to answer the questions: How is it possible to create new innovative and interdisciplinary teaching approaches, that enhances the pupils' understanding of food and a healthier lifestyle? And how can we develop interdisciplinary methods and learning tools that can be implemented as hands-on activities in multiple school subjects? To answer these questions we will introduce Learn4Health, an EU Erasmus + Strategic Partnership with the aim of creating, strengthening and sustaining health, nutrition and food literacy among pupils in primary and secondary schools in Europe. We will discuss three of the projects created within Learn4Health, and their content, structure and use, and further, analyse their innovative and interdisciplinary approaches to the issues at hand. Next, we will highlight one of these projects, the mobile Sprout Wagon as a prime example. The Sprout Wagon, with its unique mobile construction provides pupils with hands-on learning contexts in multiple school subjects, placing food, nutrition and health on the schedule, and we will discuss how this new, innovative and interdisciplinary approach, can be used as an effective tool inside the classroom to support and facilitate learning in multiple school subjects.

Finally, on this background we will present the detailed instructional guides and teaching material which will be developed during the process of the Sprout Wagon and the other Learn4Health projects and which will all be included in the HOFA Handbook - an instructional handbook which will be freely available on the Learn4Health website at the end of the project period. This dissemination strategy will ensure that the insights, innovative approaches, knowledge and experiences will be shared across the borders, thereby securing sustainability of the project and creating wide-reaching impact - and, ultimately, happier, more food literate children.
\end{abstract}

\section{Keywords:}

Health, children, food, food systems, nutrition, problem-based learning

JEL Classification: 100, C90, D69 


\section{Introduction}

Teaching children about food, health and nutrition is an essential part of not only securing the public health and wellbeing of future generations, but also to ensure a more balanced and sustainable environment and world. There is a tendency that children are increasingly more and more detached and disconnected from the food they are eating; the origins of its components, and the process 'farm to fork'. This is an issue with wide-reaching consequences to health.

Health is an individual state that every human possesses, yet it is individual at what stage each health is bound. According to the World Health Organization (WHO) "A healthy diet helps protect against malnutrition in all its forms, as well as noncommunicable diseases (NCDs), including diabetes, heart diseases, stroke and cancer" (WHO 2015). In continuation, a healthy diet often equals a healthy state, which can be seen in relation to individual eating habits and choices. Research shows that eating habits and choices are established in our earlier years and with a continuing feeling of disconnectedness from food and the origin hereof, the habits and choices are seen to follow.

Consumers, and especially children, in the globalized food systems are increasingly disconnected from understanding both how and where their food is produced. The increasing lack of understanding about the origins of food, its production and processing, poses a challenge to public health, as it causes an increase in the consumption of highly processed food, and therefore increasing obesity rates and various diet-related issues (Dyg, 2014: p.7). Furthermore, the disconnectedness between consumer and food systems also affect the environmental awareness, and other ethical dilemmas such as animal welfare and fair, sustainable trading (Dyg, 2014) (Clausen \& Fisker, 2017).

According to Dyg (2014), the school is an essential arena to address this knowledge gap; an ideal environment to nurture a connection and understanding between children and nature, a good context for promoting health and an understanding of food and food production. This has added benefits; research underpins and documents what educators already know: Healthy pupils and students are better prepared to learn (Kristjánsson et al., 2010; KL, 2015). It is on the basis of these issues, and on the understanding of the school as an essential arena that the Learn4Health project was started.

Learn4Health is an EU Erasmus+ Strategic Partnership with the aim of creating, strengthening and sustaining health, nutrition and food literacy among pupils in primary and secondary schools in Europe. Learn4Health seeks to educate young children about food and health, and to promote a better and broader knowledge of the origin of food, the food systems, and the environment, and thus, to be able to act on the basis of this knowledge, to create a healthier self and a better world. This EU Erasmus+ Strategic Partnership includes twelve partners in total, representing the 6 
European countries; Denmark, Spain, Slovenia, The Netherlands, United Kingdom and Lithuania. Each country is represented by one higher educational institution and/or health organization, and one primary and/or secondary school.

Within the Learn4Health project there is great focus on the concept of foodscapes,a concept originated in the field of geography (Aldrich, 1966) interpreted like a concept that ".. represents a marriage between food and landscape, both the conceptual notion of landscape and actual, physical landscapes" (Adena, 2006: p.13). Like landscapes, foodscapes can refer to physical and tangible spaces, however, they can also refer to intangible associations between places and food(s) (Adena, 2006). According to Mikkelsen (2011), foodscapes deal with the complex interrelationship between food, place and people.

The concept of foodscapes is therefore multivalent, understood as a concept centered around food environments, as spaces meant for talking about food, for acquiring, preparing and gathering some kind of meaning from food (MacKendrick, 2014). The concept of foodscapes is widely used in the fields of public health and urban studies to refer to urban food environments (MacKendrick, 2014). In sociology, the concept has been extended so that it includes cultural spaces and discourses that mediate our relationship with our food and institutional arrangements (MacKendrick, 2014).

In the Learn4Health context, it is relevant and essential to include the notion about foodscapes, as the project is carried out in various foodscapes such as school foodscapes. Furthermore, it is much acknowledged that especially school meals constitute a situation where learning about nutrition and food occurs (Osowski, Göranzon and Fjellström, 2011; Nahikian-Nelms, 1997; Gullberg, 2006; National Food Administration, 2007; Lintukangas, 2009). Based on this there is a focus on the theme innovative school foodscapes for future primary and secondary schools within the Learn4Health project. By integrating innovative tools and designs for learning and experimenting in specific school foodscapes, Learn4Health will strengthen the future role of subjects related to food and health in primary and secondary schools (Clausen \& Fisker, 2017).

Every day, in Universities across the globe, courses are being created to embrace blended learning approaches. Classes are now being developed with focus on more effective learning and better student outcomes (Jones, 2016). However, the concept of blended learning between higher educational institutions and public schools, like within Learn4Health, is relatively new (Clausen \& Fisker, 2017). In the Learn4Health project, the method of problem-based learning is broadly implemented; using food, health, eating and nutrition as underlying learning occasion with the aim of supporting the development of both basic and interdisciplinary skills, entrepreneurial, engineering and digital skills as well as language skills qualifications (Clausen \& Fisker, 2017; Kofoed \& Fisker, 2005). 
Learn4Health uses innovative pedagogical approaches and as previously mentioned problem-based learning, but also whole school approach, student-centered supportive learning, open school, supportive learning, intergenerational learning and co-creation, and is based on an evidence and research-based approach to knowledge creation (lbid.). This means that all interventions and activities in Learn4Health are investigated with validated methods. Learn4Health has special emphasis on creating inclusion across social and ethnic barriers by using learning about the everyday life topic of food and eating as the pivotal point (Clausen \& Fisker, 2017). Learn4Health is about having fun and at the same time developing lifelong food literacy skills to understand the nature of food and our own impact as consumers and citizens on our health status, the environment, and on social and economic factors.

\section{Focusing on Children and Health}

In this paper, we will focus on the issues connected to children and health. Specifically, we will focus on the possibilities of new, innovative approaches, i.e. innovative and interdisciplinary teaching methods and learning contexts, aiming at teaching children about food, nutrition and health, and strengthening their understanding of the origin of food, and the structure of food production. We will begin with an overview of the most debated issues related to the topic of children and health, creating a frame from which we will identify some crucial focal points to engage with. This paper will seek to answer the questions:

How is it possible to create new innovative and interdisciplinary teaching approaches, that enhances the pupils' understanding of food and a healthier lifestyle? And how can we develop interdisciplinary methods and learning tools that can be implemented as hands-on activities in multiple school subjects?

Based on this, we will discuss three of the projects created within Learn4Health, and their content, structure and use, and further, analyse their innovative and interdisciplinary approaches to the issues at hand. Next, we will highlight one of these projects, the mobile Sprout Wagon, and discuss its new, innovative and interdisciplinary approach, and how it is used as an effective tool inside the classroom to support and facilitate learning in multiple school subjects. Furthermore, we will discuss the wide applicability of the Learn4Health projects, specifically the Sprout Wagon, by introducing the HOFA Handbook; an instructional guide to the featured projects, which will be made available for schools across Europe as the final product at the end of the Learn4health project period. 


\section{Disconnected from food}

In an institutionalised world where children spend most of their day in school and away from home, the meal, and food in general, has changed as well. In continuation hereof, the availability of processed and fast food has increased in regards to the food demands children and parents require in the everyday life. The supply and demand of food has changed, and the food service sector is following readily, fueled by their own interests. We are convinced that this has a negative effect on children's perception of food and creates a disconnect between them and the understanding of food as well as 'farm to fork'.

It is our thesis that getting children back to the roots and teaching them about the origin of food, could create awareness in regards to health, nutrition and environment, in order for the children to act upon this knowledge in a beneficial and healthier way than currently.

Another important issue to focus on is the worldwide increase in child obesity, which makes reason for action. Disconnectedness from the origin of food in combination with the availability and affordability for processed food, obesity is increasing worldwide (WHO 2017). According to World Health Organization (WHO), obese children have a tendency to continue being obese in adolescence and adulthood, which is why it is preferable to act upon obesity at an early stage to avoid health problems later in life. Malnutrition in every form is often influenced by every aspect of the environment, since the environment contributes to children's perception of food. In line with the increasing amounts of processed food and food prepared out of home, the healthy foods are also seen to be combined with poor availability and affordability, which is yet another fact contributing to children's disconnectedness from the origin of food (WHO 2017).

Additionally, children have, due their age and as part of the development, a tendency to fear unknown foods and being influenced by the surrounding environment both culturally and socially (Bai et al. 2014; Houldcroft, 2014). Taste and preferences for specific foods are established early in life, which is why it is of great importance to establish healthy habits in the childhood. Consuming fruit and vegetables as part of a habit in childhood is an important predictor to the same habits in adulthood and thereby contributes to a healthy lifestyle avoiding lifestyle-related sickness as noncommunicable diseases (Heimendinger \& Van Duyn, 1995; Crockett \& Sims, 1995).

It is the thesis of the authors of this paper, that the school is an important arena for these habits to set due to the amount of time spent there. The surrounding environment contributes to how every individual act when eating (WHO 2017). An example of this is the project from 2009 Veggiecation, which was established by Lisa Surian. Veggiecation is a program designed to create a positive environment leading to a favourable attitude towards vegetable consumption with third graders during the nine months of school year. The program affected the school environment with poster displays, nutrition 
education in classrooms and vegetable tastings in lunchrooms and is due to its effective methods now implemented in over 30 US states as well as in Canada (Bai et al., 2014).

Another method to empower pupils to act healthier is the use of school gardens. The integration of gardens in schools changes the school environment into an arena where learning comes in different forms, both theoretical and practical. Furthermore, it visualises food and the origin hereof in a new way, that is seen to have an effect on the children's behavior in regards to food and the environment but also to each other, to the teachers and to the school in general (Dyg 2014, Dyg \& Wistoft, 2018; Poston et al., 2005; Bai et al., 2014).

Additionally, the school environment represents one of the most significant arenas when aiming for a behavioral change in children, namely the concept of role modelling and the act of modelling. According to Albert Bandura and the Social Learning Theory, modelling has a significant influence on children, which is why role models can be useful to get children to consume more fruit and vegetables and change their attitude (Lowe, 2014). Role models can be cartoon characters and TV-celebrities, but it can also be friends, peers, teachers and parents, who all either separately or as a community impact the child and its behavior. Children often have a high tendency to copy a model, they admire, who are similar in age or older (Lowe, 2014; Houldcroft et al., 2014). Peers and friends are seen as a central source of influence on children's eating behaviour and habits (Bai et al., 2014; Houldcroft et al., 2014). This is due to the fact that time spent away from home in company with peers, makes the individual child model oneself to fit the surroundings, their friends and the environment they act and eat in, as well as finding oneself (Houldcroft et al., 2014). Being around friends and succeeding with a task individually or in a group can create a sense of community that will motivate to further work and peer-to-peer will be a contributing factor.

When looking at the facts, the authors of this paper find it relevant to include hands-on practices in the aim of empowering children to act more beneficial concerning their own as well as their families' health now and in the long term. Recent years several experiments have been made as part of studies concerning children and health and especially school gardens have been concluded as a useful tool to strengthen pupil's food knowledge, nutritional and environmental awareness as well as their self-efficacy in the school garden (Dyg, 2014; Poston et al. 2005; Graham et al., 2005; Nanny, 2007).

Additionally, school gardens have shown to have an effect on pupils' fruit and vegetable preferences as well as their intake. Pupils participating in school garden programs have a greater knowledge in fruit and vegetables and the origin hereof, as school gardens often focus on the entire process from 'farm to fork'. Not only do the pupils get new knowledge, they learn to act upon the knowledge during hands on activities that strengthens their self-efficiency. It creates a sense of connectedness and ownership to what has been grown and produced in their own school garden. 
It is on the basis of the issues presented above that we have formulated the questions of this paper, which will be discussed in the following.

\section{New, Interdisciplinary and Innovative Methods}

The questions of this paper are some of the focal points of the Learn4Health project; creating new, interdisciplinary and innovative methods and hands-on learning context for pupils with the aim of strengthening their understanding of food and food systems and enhancing their food literacy.

One such project created within the Learn4Health project is the Sprout Wagon.The Sprout Wagon is a mobile steel construction on wheels; a wagon, designed to carry trays of sprouts, complete with its own adjustable water and light system. It is designed as a micro system to mirror natural conditions with the intention of providing pupils with an educational and hands-on approach to learn about the process of growing their own sprouts. The Sprout Wagon is designed and constructed in an interdisciplinary collaboration between architects and engineers at Aalborg University and school teachers at Arden School in Denmark. The Sprout Wagon is based in a common area alongside the school canteen, but its mobile design makes it possible to move into the classrooms, where it can be used in experiments in multiple school subjects. The aim is to make use of the Sprout Wagon in a wide range of relevant science subjects; the adjustable light, water and temperature makes it possible for pupils to experiment with measuring, calculating, and administering the necessary nutrition for the sprouts to grow and flourish. Complex concepts such as the photosynthesis can be illustrated, taught and explained in an understandable, hands-on way. The fruits of this collaborative effort between pupils and teachers, the various sprouts, are then available for pupils to harvest for their lunch, or used in home economic classes.

Another project within the Learn4Health project, also at Arden School is the Squash Competition. The Squash Competition is a new hands-on learning context and program that engages pupils and teachers in a school garden program. A pedagogical program oriented towards the teachers which further links the classroom to the natural surroundings (Larsen, 2018). Primarily, the program contains a Squash-growing competition, but it has a wide applicability as it could be focusing on any other vegetable depending on the surrounding possibilities i.e. season and country.

The Squash competition is based on a learning guide constructed for the teachers to involve the students in growing the most amounts of squash measured in kilos. The teacher manual is meant as a guide which aims to involve the children in the knowledge of growing vegetables. The children learn first and foremost about photosynthesis. Secondly, they are to search, find, read and conclude upon the most beneficial way to grow their vegetable, in this case the squash, and thereby establish a hypothesis on what they believe would be the most beneficial circumstances to grow the largest 
amount of squash in kilos (Larsen, 2018). The pupils are then to weigh and measure the growing squash during the period, and at a certain deadline, harvest their crop. The program is designed to take place in several educational surroundings i.e. school garden, the classroom, the kitchen etc. Concurrently with the growing experiment the intention is to collect, prepare and taste healthy dishes containing squash and finally share their whole experience with Learn4Health participating schools and partners (Larsen, 2018).

In the long term, the aim is to increase the pupils' knowledge of the food they eat, to empower them and give them the ability to choose food beneficial for their health, and having fun while they do it. By making it a competition, the learning process can be experienced as a game and create a fun context, which can benefit the learning progress as well as the interaction between the children. Furthermore, it can provide the pupils with a sense of self-confidence and creating new friendships across class divides, year group etc. and thereby stimulating and improving social abilities (Lowe, 2014; Dyg \& Wistoft, 2018).

A third project within Learn4Health worth mentioning in this context is the WannaB Foodie Entrepreneur, a project made in a collaboration between the two Slovenian partners, the France Prešeren Črenšovci Primary School, and the Centre for Health and Development Murska Sobota. The project involves school-owned raised garden beds, where the pupils will grow and cultivate traditional herbs and crops. The harvested results will be showcased and sold at stands manned by the pupils at a local market and festival, where local food and culture is promoted. The intended impact of this project is a better understanding of food origins and production for the pupils, but also the strengthening of their entrepreneurial skills. The new and innovative aspect of the project is that the pupils will not only be involved with the growing of herbs and crops, thereby connecting them to nature, but they will harvest their crops and sell them, which will teach them invaluable, practical skills in the field of small businesses. The involvement in the local festival and markets is further intended also to preserve local culinary culture and history; stressing the importance of healthy, local food for both pupils and their families. It is also the intention to strengthen the intergenerational connections; connecting kindergartens, school and the local community.

Several studies show the connection between school gardens and garden-based learning and nutritional and environmental awareness, well-being as well as new learning achievements (Dyg, 2014; Dyg \& Wistoft 2018; Waliczek \& Zajicek, 1999). The Sprout Wagon, Squash Competition and WannaB Foodie Entrepreneur are all examples of how new, interdisciplinary and innovative approaches to school gardens and garden-based learning can be developed in praxis. These projects are all designed to fit Learn4Healths overall aim of creating new interdisciplinary ways to promote the understanding of health, food and nutrition, in specific the origin of food to children (Larsen, 2018). 
When initiating projects focusing on 'farm-to-fork', the origin of the food as well as the nutritional aspect is at focus. Processed and fast food supply is increasing, the general understanding of food and its origin is being neglected and the disconnectedness is growing, which makes this, the time to focus on food and its origin. During the years several studies have supported this; it is quite clear that getting your hands dirty, talking about, seeing, tasting and touching the food contributes to the general understanding and knowledge about the origin of food (Waliczek \& Zajicek, 1999; Dyg 2014). Furthermore, understanding the concept of "farm-to-fork" gives new insights and can contribute to understand what food is, where it comes from and how it affects nutritionally and environmentally (Dyg \& Wistoft, 2018; Bai et al. 2014).

One of the cornerstones of the Learn4Health project is to educate the children on how to make healthy and sustainable choices - both now and in the long term. The nutritional aspect of learning about vegetables is an indisputable fact, as vegetables are often connected to health. Health and health state is often associated with the abovementioned disconnectedness. As processed food and several food products are constantly providing us with possibilities, opportunities and availabilities, the general health is at stake. An increase in child obesity is occurring at national as well as international plan (WHO 2017), why the nutritional aspect of growing and knowing vegetables is of great importance as mentioned previously (ibid.).

The three Learn4Health projects, The Sprout Wagon, The Squash Competition and The WannaB Foodie Entrepreneur provide the children with new learning abilities on individual plan as well as in groups (Dyg 2014). The children have the opportunity to work with and learn about new methods, possibilities - all this in new surroundings that might inspire them in a new way. Every identity is unique, but can change depending on the surroundings and the people one surrounds with and garden-related projects like these can lead to a new way of thinking and seeing oneself (Dyg \& Wistoft, 2018).

We want to highlight that the contexts and activities of the projects can create a sense of community and create strong social bonds, it can also make the children socialise with each other bridging age, culture, gender etc. and in specific in this setting create bonds in between the class and create new communities (Dyg \& Wistoft, 2018; Bai et al., 2014). Additionally, they can create a sense of empowerment as the children are working in groups learning from each other, modelling for each other in a so-called Peerto-peer method (Bandura, 1977; Lowe, 2014; Dyg \& Wistoft, 2018).

In regards to the Squash Competition and the Sprout Wagon, the children are learning from each other in groups, creating new communities and experience a higher level of fellowship. They exchange knowledge and strengths and experience a sense of empowerment and self-confidence when they succeed. Their self-efficacy will increase, which is often the bearing factor for the implementations to prolong (Houldcroft et al., 2014). 
Designing The Sprout Wagon, the Squash Competition, and the WannaB Foodie Entrepreneur create new foodscapes where food is more visible, causing new room for interaction. It forces the children to think about vegetables, crops and sprouts and to have an opinion on these as well as share their point of view with peers.

The accessibility and availability becomes more near and creates room for daily integration of crops, making hands on activities and implementation in other school activities. A proposal could be math when measuring and weighing their home-grown crops in the process of creating the most optimal and beneficial surroundings when growing e.g. squash or working with raised garden beds. Accessibility and availability has shown to have an affect on children's consumption, additionally visualising food in the daily, in posters or by having a Sprout Wagon in the canteen or classrooms, is seen to create new awareness of the specific crops (Bai et al., 2014).

The involved school partners in the mentioned projects highlight that the ability of the pupils involved in these projects are stimulated and strengthened in regards to exploring the field of natural science. Growing crops requires acquainting yourself with how to create the optimal surroundings, for the crops to actually grow. This includes information about wind, water, soil and temperature that forces the children to think about the environment.

'Garden for Bellies' have recently shown how the school gardening showed side effects as the children showing empathy with animals and plants and seeing themselves as part of the nature (Dyg \& Wistoft, 2018). Furthermore, the attitudes towards the nature and surroundings when being in Gardens for Bellies were experienced more positive (Ibid.) Another study, Project GREEN, made in Kansas and Texas, US focusing on improving environmental attitudes through a school garden program gave an insight into similar results. The students were significantly more positive towards environmental issues after participating in the school garden program regardless of duration (Waliczek \& Zajicek, 1999). Within the Learn4Health projects there is a focus on the environment; the pupils involved are taught about seasonality, locality and sustainability, all with the aim of empowering the children to act on the basis of this knowledge when going to the supermarket, buying groceries (Larsen, 2018).

\section{The Sprout Wagon - A New Interdisciplinary Learning Tool}

The school is not only an arena for change, but also a place that can recall memories and friendships as well as an environment, where children should feel safe and seek comfort, due to the amount of time spent in school. In Denmark, a child is in school eight hours a day, five days a week, nine months a year on average, which means that this arena needs to be a comfortable space, with an environment beneficial for children to develop, both physically, mentally and socially. Additionally, for a child to participate in school, health is important, and an environment that embraces all of these aspects is, 
according to the authors of this paper, an environment beneficial for children and their development.

Earlier in this paper, we raised the question on how to create such an environment through a new innovative approach that includes interdisciplinary methods and pedagogical tools to implement in multiple school subjects inside the classroom. On the basis of earlier studies concerning children and health, and the fact that they also emphasis the school as an important arena with focus on the school environment, Learn4Health has invented and designed the Sprout Wagon to enhance exactly this.

The Sprout Wagon is developed with the aim of reducing the distance between children and food and food production, and with the intention of forging a stronger connection between classroom and nature. The pupils get a chance to get their hands dirty; touching, smelling and tasting the sprouts while they learn, which creates a learning context with great possibilities. While working with growing the sprouts, the pupils will get involved with learning about the specific sprout, and they learn about how to gain and collect knowledge to set the best premises for growing vegetables in their natural surroundings. Furthermore, they get an insight into the concept of 'farm-to-fork', and learn about how to ensure and secure food safety. These learning contexts provide the pupils with an increased environmental awareness and crucial knowledge about nutrition (Dyg \& Wistoft, 2018). The Sprout Wagon will have a base in the common area next to the canteen at Arden School, but its mobile construction makes it rather unique: The Sprout Wagon can be moved around the school and into different classrooms, and therefore be implemented in multiple settings, contexts and subjects, where the pupils can use it for various experiments. This is an innovative approach that includes new interdisciplinary methods and pedagogical tools to create a learning context where pupils are able to get their hands dirty, and strengthen their connection and understanding of nature in novel, creative ways. The Sprout Wagon, therefore, offers a prime representation of the overall aim of Learn4Health; developing new, interdisciplinary and innovative approaches to educate children about food, food production, nutrition and health. What is more, to secure the intention of wide applicability and transferability of the insights and detailed information about the Sprout Wagon project will be included in the Learn4health HOFA Handbook, a complete instructional guidebook offering detailed instructions and curricula guides to the different Learn4Health projects. Teaching material for both students and teachers, and instructional guides and blueprints, the construction of the wagon is being developed in connection with the implementation and subsequent evaluation of the Sprout Wagon. These thorough guides and manuals will ensure that other EU schools interested in doing a similar project will have a finished "recipe" for building and implementing their own sprout wagons. All this material will be collected in the Learn4Health HOFA Handbook. The HOFA Handbook will be produced as a book in PDF format and be available through the Learn4Health website at the end of the project, freely accessible for all interested schools across Europe. This open access will secure wide applicability, dissemination and great transferability. The HOFA Handbook will secure the 
sustainability of the Learn4Health project, as the insights, experiences and the knowledge accumulated within the project period will be passed on to a wide audience, easily available for application, and therefore also optimising the overall impact.

\section{Conclusion}

We are witnessing a tendency in today's globalised food systems, where children are increasingly more and more disconnected from the food they are eating, from understanding the origins of food and from the process 'farm to fork'. This is an issue with potentially wide-reaching consequences to the overall public health and wellbeing, but also a challenge in regards to securing a sustainable environment and world.

Learn4Health is an EU Erasmus+ Strategic Partnership consisting of twelve partners representing 6 European countries which aims to create, strengthen and sustain health, nutrition and food literacy among pupils in primary and secondary schools in Europe. The Learn4Health project has developed new, interdisciplinary and innovative approaches, i.e. innovative teaching methods and learning contexts, aiming at teaching children about food, nutrition and health, providing hands-on learning contexts to strengthen their understanding of the origin of food, and the structure of food production. This way, Learn4Health strives to promote food literacy and educate children to be able to act on the basis of this knowledge, to create a healthier self and a better, sustainable world.

The development and construction of the mobile Sprout Wagon, The Squash Competition and the WannaB Foodie Entrepreneur are all examples of how the Learn4Health project has developed new, interdisciplinary and innovative approaches to educate pupils within the field of food literary. We have highlighted the Sprout Wagon as a prime example, as its unique mobile construction provides pupils with hands-on learning contexts in multiple school subjects, placing food, nutrition and health on the schedule. Furthermore, the detailed instructional guides and teaching material, which will be developed during the process of the Sprout Wagon and the other Learn4Health projects in the HOFA Handbook, will be freely available on the Learn4Health website at the end of the project period. This dissemination strategy will ensure that the insights, innovative approaches, knowledge and experiences will be shared across the borders, thereby securing sustainability of the project and creating wide-reaching impact - and, ultimately, happier, more food literate children.

In the process of improving the food literacy of the pupils, Learn4Health has developed and designed new, innovative and interdisciplinary teaching approaches that enhances the pupils' understanding of food and health. By presenting and discussing projects like The Sprout Wagon, The WannaB Foodie Entrepreneur and The Squash Competition, we have shown how it is possible to develop new interdisciplinary methods and learning tools that can be implemented as hands-on activities in multiple school subjects. 


\section{References:}

Adena, P. (2006). Festive foodscapes: iconizing food and the shaping of identity and place. Ph.D. Austin, Texas: The University of Texas.

Aldrich, R. I. (1966). The Development of “-Scape”. American Speech, 41(2), pp. 155-157.

Cardwell, V.B. (2005). Literacy: What Level for Food, Land, Natural Resources, and Environment?. Journal of National Resources and Life Sciences Education, 34, pp. 112-117.

Bell B M., Martinez L, Gotsis M, Lane H. C, Davis J N., Antunez-Castillo L, Ragusa G, and Spruijt-Metz D. (2018). Virtual Sprouts: A Virtual Gardening Pilot Intervention Increases Self-Efficacy to Cook and Eat Fruits and Vegetables in Minority Youth. Games for Health Journal. 7 (2), pp.127-135.

Bai, Y., Suriano, L., Wunderlich, S.M. (2014). Veggiecation: A Novel Approach to Improve Vegetable Consumption Among School-Aged Children: Journal of Nutrition, Education and Behaviour. 46 (4), pp.320-321.æ

Clausen, K. \& Fisker A.M (2017). Learn4Health, an European project creating health and food literacy through innovative interdisciplinary teaching and learning methods. in: Proceedings of the 4th Teaching \& Education Conference, Venice, May 2017, pages 53-59

Crockett, S.J., \& L. Sims. (1995). Environmental Influences on Children's Eating. Journal of Nutrition Education. 27, pp. 235-249.

Dyg, P. (2014). Fostering Food Literacy and Food Citizenship through Farm-School Cooperation and beyond. Ph.D. Aalborg, Denmark: Department of Civil Engineering, Aalborg University.

Dyg P M. \& Wistoft K. (2018). Wellbeing in school gardens - the case of the Gardens for Bellies food and environmental education program, Environmental Education Research, DOI: $\underline{10.1080 / 13504622.2018 .1434869}$

Graham, H. et al. (2005). Use of School Gardens in Academic Instruction. Journal of Nutrition Education and Behavior. 37(3), pp. 147-151.

Green, V. (2004). An exploration of school gardening and its relationship to holistic education. Ontaria, Canada: University of Guelph.

Gunter, B. and McAleer, J. (2004). Children and television. 1st ed. London: Routledge.

Heimendinger, J. \& M. Van Duyn. (1995). Dietary behavior change: the challenge of recasting the role of fruit and vegetables in the American diet. American Journal of Clinical Nutrition, 61, pp. 1397S$1401 \mathrm{~S}$.

Jones, M. (2016). A Case Study of Blended Learning in Higher Education in Malaysia: Flipped, Flopped or Forgotten? In: Proceedings of the 3rd Teaching \& Education Conference. Barcelona 2016, pp. $132-137$.

KL, (2015). Sunde børn lærer bedre. Copenhagen, Denmark: Center for Forebyggelse i Praksis. Available at:

http://www.kl.dk/ImageVaultFiles/id_72480/cf_202/KL_Sunde_boern_laerer_bedre_.PDF[Access ed 8 Apr. 2017] 
Koefod, L. \& Fisker, A.M. (2005). Changing curriculum bit by bit.

Published in Proceedings of the 4th ASEE/AaeE Global Colloquium on Engineering Education, Sydney, September 2005

Kristjánsson, Á., Sigfúsdóttir, I. and Allegrante, J. (2010). Health Behavior and Academic Achievement Among Adolescents: The Relative Contribution of Dietary Habits, Physical Activity, Body Mass Index, and Self-Esteem. Health Education \& Behavior, 37(1), pp.51-64.

Larsen, V. A. (2018). Teacher Manual for Soil'n Garden program (SGP). Arden, Denmark.

MacKendrick, N. (2014). foodscape. Contexts, [online] (Summer 2014). Available at: https://contexts.org/articles/foodscape/[Accessed 2 Apr. 2017].

Marilyn S. Nanney, Sheldon Johnson, Michael Elliott and Debra Haire-Joshu. (2007). Frequency of Eating Homegrown Produce Is Associated with Higher Intake among Parents and Their Preschool-Aged Children in Rural Missouri. Journal of the American Dietetic Association, Volume 107(4), pp. 577-584.

Mikkelsen, B. (2011). Images of foodscapes: Introduction to foodscape studies and their application in the study of healthy eating out-of-home environments. Perspectives in Public Health, 131(5), pp.209-216.

Osowski, C., Göranzon, H. and Fjellström, C. (2011). Children's understanding of food and meals in the foodscape at school. International Journal of Consumer Studies, 36(1), pp.54-60.

Poston, Suzanne A., Shoemaker, Candice A., and Dzewaltowski, David A. (2005). A Comparison of a Gardening and Nutrition Program with Setting. HortTechnology. 15(3), pages 463-467.

Skelly, M.S. and Bradley, C.J. (2007). The growing phenomenon of school gardens: Measuring their variation and their effect on students' sense of responsibility and attitudes toward science and the environment. Applied Environmental Education and Communication, 6(1), pp. 97- 104.

Vidgen, H. (2016). Introduction: Food literacy for contemporary food and eating. In: H. Vidgen, ed., Food Literacy, 1st ed. London, UK: Routledge, pp.1-17.

Waliczek, M.T., Bradley, C.J. and Zajicek, M.T. (2001). The effects of school gardening on children's interpersonal relationships and attitudes towards school. HortTechnology, 11(3), pp. 466-468.

Waliczek, T.M., Zajicek, J.M. (1999). School Gardening: Improving Environmental Attitudes of Children Through Hands-On Learning. Journal of Environ. Hort. 17(4): 180-184.

WHO (2015). Healthy Diet. World Health Organization, Europe. [Accessed 20th May 2018]. Available at: http://www.who.int/mediacentre/factsheets/fs394/en/

WHO (2017). Commision on Ending Childhood Obesity: Facts and Figures on Childhood Obesity. Available: http://www.who.int/end-childhood-obesity/facts/en/. Last accessed 15th July 2018. 